\title{
Assessment of managerial innovation in manufacturing company
}

\author{
R Y H Silitonga ${ }^{{ }^{*}}$ and M Setiawati ${ }^{1}$ \\ ${ }^{1}$ Department of Industrial Engineering, Harapan Bangsa Institute of Technology, \\ Bandung, Indonesia \\ *roland@ithb.ac.id
}

\begin{abstract}
Every company has to develop their managerial capability to maximize performance of every function in order to survive in an environment with drastic changes right now. This research was conducted at two governments owned manufacturing companies to compare the differences in managerial innovation. The method to assess the managerial innovation was based on elements of management function, which are planning, organizing, leading, controlling and coordinating. There were two methods in collecting the data, using questionnaire and doing observation. Questionnaires results were calculated using BPMSG AHP online system, to determine the score. The higher score of managerial innovation, the higher potential of the company to innovate. Managerial innovation score were $42.3 \%$ and $48.9 \%$, which showed that none of them were innovative based on the previous research standard, which stated that innovation potential should be more than $50 \%$. The differences between the two were also analysed based on every management function.
\end{abstract}

Keywords: managerial innovation, management functions, manufacturing company

\section{Introduction}

Innovation is a process of turning ideas into reality and making it capable to create social values. Innovation is the key to success in companies. Innovative companies have greater potential to achieve success when compared to non-innovative companies (1). A Turkish research describes a methodology to assess managerial innovation in manufacturing industries (2). The assessment was based on the evolution of each management functions. Evolution means that five management functions: planning, organizing, leading, controlling, and coordinating, changes in its process. The Research gives weight to every dimension of existing management functions. Biggest weight adjustment is given to newest element of every management function (related to technological and social change).

This research used the methodology to assess two manufacturing companies. The result was analysed to produce a managerial improvement in order to increase innovation. Damanpour \& Aravind's (3) concept supported the method by explaining the significant correlation between managerial innovation with innovation management where companies with high managerial innovation level $(>50 \%)$ have potential to innovate and create values.

The rest of this paper is organized as follows. Section 2 introduces the definition of managerial innovation, comparison between five management functions and its element, and the assessment of 
managerial innovation. Section 3 explains the research method. Section 4 presents the managerial innovation results of the two manufacturing companies. Section 5 discussed the comparison and analysis to each management function for both companies. We close with some conclusions and further research suggestions in section 6 .

\section{Managerial Innovation Assessment}

Managerial Innovation is the capability to handle the changes occurring in the management functions, in the most appropriate way (2). Managerial innovation is also the implementation of new organizational structures, administrative systems, management practices, processes, and techniques that could create value for the organization (4). Managerial innovation is measured through the evolution level of management functions (see figure 1). Each evolution level has its own version of management functions (see figure 2). Hence Managerial Innovation can be assessed by observing five management functions (planning, organizing, leading, controlling, and coordinating) at each level of evolution. Each level of evolution have different weight at each functions. It shows that the higher the level of management function, the higher potency of the company to make something innovative. The relative weight of each element in figure 2 can be found in table 1 .

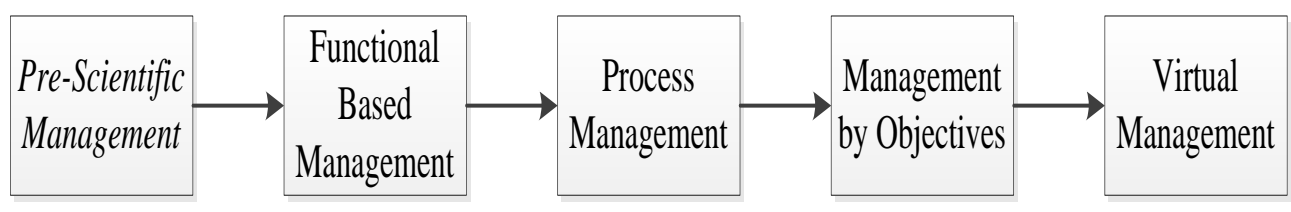

Figure 1. Management evolution.

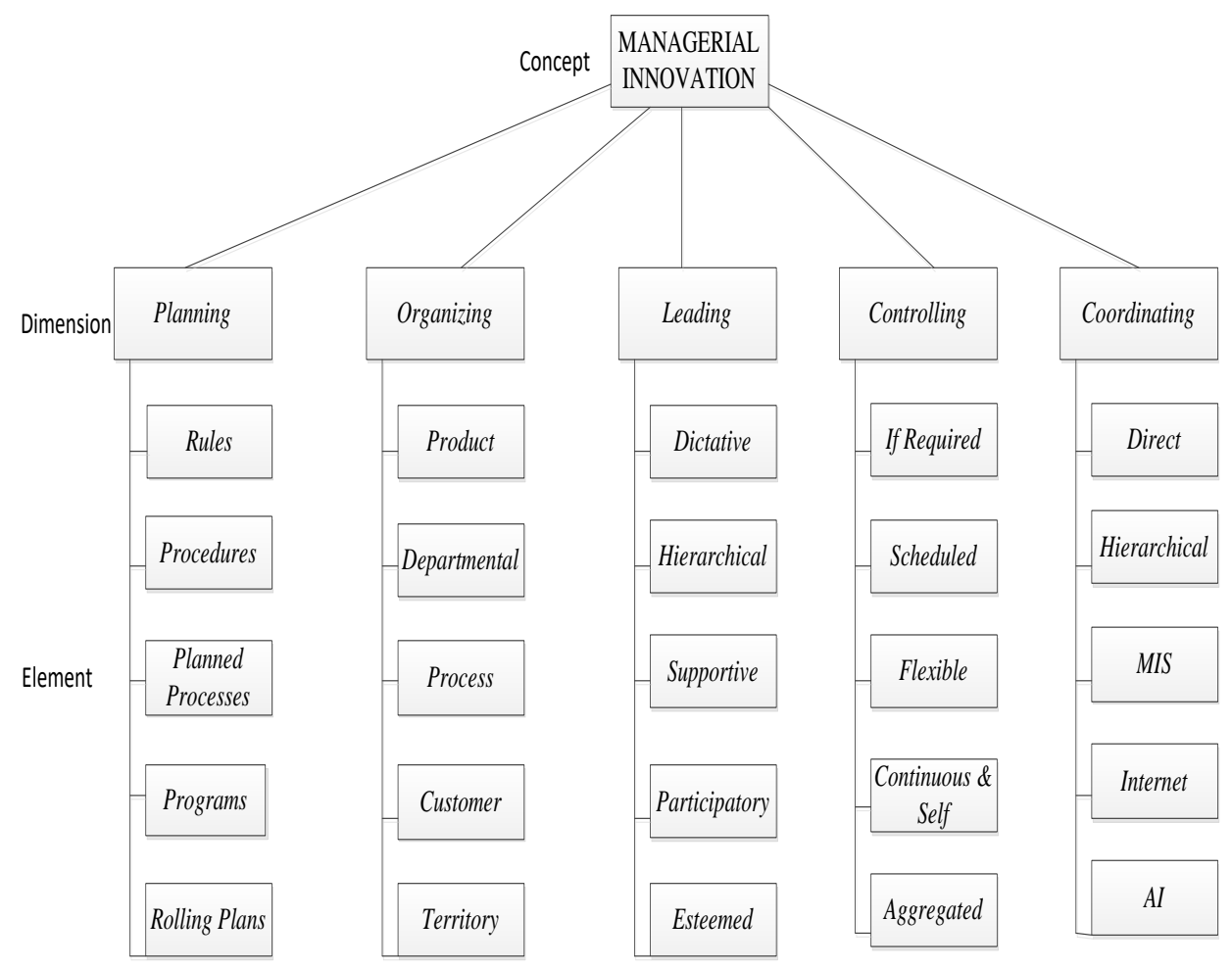

Figure 2. Element in management function. 
Table 1. Specific Management Functions with Weights.

\begin{tabular}{|c|c|c|c|c|c|c|}
\hline $\begin{array}{l}\text { Manufacturing } \\
\text { types }\end{array}$ & Planning & Organizing & Leading & Controlling & Coordinating & $\begin{array}{l}\text { Relative } \\
\text { weight }\end{array}$ \\
\hline $\begin{array}{l}\text { Prescientific } \\
\text { Management } \\
\text { Departmental }\end{array}$ & Rules & Product & Dictative & If required & Direct & $2^{0}$ \\
\hline Management & Procedure & Department & Hierarchy & Scheduled & $\begin{array}{l}\text { Hierarchy } \\
\text { Management } \\
\text { Information }\end{array}$ & $2^{1}$ \\
\hline $\begin{array}{l}\text { Management } \\
\text { Management }\end{array}$ & Planned Process & Process & Supportive & Flexible & System & $2^{2}$ \\
\hline Objective & Programme & Customer & Participatory & Continuous & Internet & $2^{3}$ \\
\hline $\begin{array}{l}\text { Virtual } \\
\text { Management }\end{array}$ & Rolling Plans & Territory & Esteemed & Aggregate & $\begin{array}{l}\text { Artificial } \\
\text { Intelligent }\end{array}$ & $2^{4}$ \\
\hline
\end{tabular}

To measure the managerial innovation level of a company, every observation of management functions should be put into the equations below.

$$
\begin{aligned}
& \mathrm{Pf}=\frac{\text { weight rule } x \%+\text { procedure } x \%+\text { program } x \%+\text { processes } x \%+\text { rolling plan } x \%}{\text { Total weight of planning function }} \\
& \mathrm{Of}=\frac{\text { weight product } x \%+\text { department } x \%+\text { process } x \%+\text { customer } x \%+\text { territory } x \%}{\text { Total weight of organizing function }} \\
& \mathrm{Lf}=\frac{\text { weight dictative } x \%+\text { structural } x \%+\text { supportive } x \%+\text { participant } x \%+\text { esteem } x \%}{\text { Total weight of leading function }} \\
& \mathrm{Cf}=\frac{\text { weight dictative } x \%+\text { if required } x \%+\text { scheduled } x \%+\text { flexible } x \%+\text { cont } x \%+\text { aggr } x \%}{\text { Total weight of controlling function }} \\
& \text { Coorf }=\frac{\text { weight direct } x \%+\text { hierarchical } x \%+\text { scheduled } x \%+\text { MIS } x \%+\text { internet } x \%+A I x \%}{\text { Total weight of coordinating function }}
\end{aligned}
$$

The managerial innovation percentage can be determined using equation:

$$
\delta \mathrm{MI}: \frac{(W p . P f)+(\text { Wo.Of })+(W l . L f)+(W c . C f)+(\text { WCoor.Coorf })}{W p+W o+W l+W c+W c o o r}
$$

$\delta \mathrm{MI}$ : Degree of Managerial Innovation

Wp : Weight of Planning Function

Wo : Weight of Organizing Function

Wl : Weight of Leading Function

Wc : Weight of Controlling Function

Wcoor: Weight of Coordinating Function
PF : Innovation in Planning Function

OF $\quad$ : Innovation in Organizing Function

LF : Innovation in Leading Function

CF : Innovation in Controlling Function

Coorf : Innovation in Coordinating Function

\section{Research Method}

There are two main activities in collecting data, both were about measuring the level of management functions activities, namely observation and experts feedback using questionnaires. The level of innovations PF, OF, LF, CF and Coorf were obtained by performing a survey and observing these functions with Head Division, Head Department, and Head Sub-Department. The weights Wp, Wo, Wl, Wc, and Wcoor are obtained through the questionnaire sent to industrial expert. 
We used BPMSG AHP Online system to process the questionnaires. By using this online system, the repetition and replication for future researches will be easier. It also has validation system so if the calculations are not consistent, the system would not give the weight.

With these results, the degree of managerial innovation was determined using equation 6 . If the result of managerial innovation less is than $50 \%$, it means that the management is not innovative enough to produce innovations.

\section{Result}

The results of observations are presented in table 2 to 6 below.

Table 2. The result of observation in Planning PT X and PT Y.

\begin{tabular}{ccc}
\hline Element & Planning PT. X & Planning PT.Y \\
\hline Rules & $96 \%$ & $99 \%$ \\
Procedure & $97 \%$ & $98 \%$ \\
Planned Process & $86 \%$ & $87 \%$ \\
Programs & $96 \%$ & $93 \%$ \\
Rolling Plans & $93 \%$ & $89 \%$ \\
\hline
\end{tabular}

Table 3. The result of observation in Organizing PT X and PT Y.

\begin{tabular}{ccc}
\hline Element & Organizing PT. X & Organizing PT.Y \\
\hline Product & $100 \%$ & $100 \%$ \\
Departmental & $100 \%$ & $100 \%$ \\
Process & $0 \%$ & $100 \%$ \\
Customer & $0 \%$ & $0 \%$ \\
Territory & $0 \%$ & $0 \%$ \\
\hline
\end{tabular}

Table 4. The result of observation in Leading PT X and PT Y.

\begin{tabular}{ccc}
\hline Element & Leading PT. X & Leading PT.Y \\
\hline Dictative & $95 \%$ & $100 \%$ \\
Structural & $92 \%$ & $99 \%$ \\
Supportive & $25 \%$ & $93 \%$ \\
Participant & $6 \%$ & $39 \%$ \\
Esteem & $0 \%$ & $0 \%$ \\
\hline
\end{tabular}

Table 5. The result of observation in Coordinating PT X and PT Y.

\begin{tabular}{ccc}
\hline Element & Coordinating PT. X & Coordinating PT.Y \\
\hline Direct & $99 \%$ & $99 \%$ \\
Hierarchical & $100 \%$ & $100 \%$ \\
MIS & $97 \%$ & $94 \%$ \\
Internet & $98 \%$ & $100 \%$ \\
AI & $0 \%$ & $8 \%$ \\
\hline
\end{tabular}


Table 6. The result of observation in Controlling PT X and PT Y.

\begin{tabular}{ccc}
\hline Element & Controlling PT. X & Controlling PT.Y \\
\hline If required & $94 \%$ & $93 \%$ \\
Scheduled & $99 \%$ & $99 \%$ \\
Flexible & $89 \%$ & $96 \%$ \\
Continuous & $96 \%$ & $63 \%$ \\
Aggregate & $2 \%$ & $17 \%$ \\
\hline
\end{tabular}

The values of each management functions levels can be obtained using equations 1-5. The scores for PT. X:

$$
\begin{aligned}
& P F=\frac{(1 \times 96 \%+2 \times 97 \%+4 \times 86 \%+8 \times 96 \%+16 \times 93 \%)}{31} \times 100 \%=93.23 \% \\
& O F=\frac{(1 \times 100 \%+2 \times 100 \%)}{31} \times 100 \%=9.68 \% \\
& L F=\frac{(1 \times 95 \%+2 \times 92 \%+4 \times 25 \%+8 \times 6 \%)}{31} \times 100 \%=13.77 \% \\
& C F=\frac{(1 \times 94 \%+2 \times 99 \%+4 \times 89 \%+8 \times 96 \%+16 \times 2 \%)}{31} \times 100 \%=46.71 \%
\end{aligned}
$$

$\operatorname{CoorF}=\frac{(1 \times 99 \%+2 \times 100 \%+4 \times 97 \%+8 \times 98 \%)}{31} \times 100 \%=47.45 \%$

The scores for PT Y:

$$
\begin{aligned}
& P F=\frac{(1 \times 99 \%+2 \times 98 \%+4 \times 87 \%+8 \times 93 \%+16 \times 89 \%)}{31} \times 100 \%=90.68 \% \\
& O F=\frac{(1 \times 100 \%+2 \times 100 \%+4 \times 100 \%)}{31} \times 100 \%=90.68 \% \\
& L F=\frac{(1 \times 100 \%+2 \times 99 \%+4 \times 93 \%+8 \times 39 \%)}{31} \times 100 \%=31.68 \% \\
& C F=\frac{(1 \times 93 \%+2 \times 99 \%+4 \times 96 \%+8 \times 63 \%+16 \times 17 \%)}{31} \times 100 \%=46.81 \%
\end{aligned}
$$

CoorF $=\frac{(1 \times 99 \%+2 \times 100 \%+4 \times 94 \%+8 \times 100 \%+16 \times 8 \%)}{31} \times 100 \%=51.71 \%$

The result of questionnaire were used to determine the degree of managerial innovation. The questionnaire sent to 30 industrial expert from PT. X and 30 industrial expert from PT. Y and were calculated by BPMSG AHP Online system. The validity of values was good because the consistency ratio is $4 \%$, which is below $10 \%$ (5). The value of Planning is $20.6 \%$, Organizing is $19.1 \%$, Leading is $21.5 \%$, Coordinating is $19.3 \%$ and Controlling is $19.5 \%$.

By calculating, every element above the score of the degree of managerial innovation in PT X and PT. Y is presented in table 7 below. 
Table 7. The result of degree of managerial innovation in PT. X.

\begin{tabular}{ccr}
\hline Management Functions & Capabilities PT. X & Weight PT. X \\
\hline Planning & $93.23 \%$ & $20.60 \%$ \\
Organizing & $9.68 \%$ & $19.10 \%$ \\
Leading & $13.77 \%$ & $21.50 \%$ \\
Coordinating & $46.71 \%$ & $19.30 \%$ \\
Controlling & $46.75 \%$ & $19.50 \%$ \\
Degree of Managerial Innovation & \multicolumn{2}{c}{$42.3 \%$} \\
\hline
\end{tabular}

$$
\delta M I=\frac{(W p \times P f)+(W o \times O f)+(W l \times L f)+(W c \times C F)+(\text { WCoor } \times \text { Coorf })}{(W p+W o+W l+W c+W C o o r)} \times 100 \%=42.3 \%
$$

Table 8. The result of degree of managerial innovation in PT. Y.

\begin{tabular}{crr}
\hline Management Functions & Capabilities PT. Y & Weight PT. Y \\
\hline Planning & $90.68 \%$ & $20.60 \%$ \\
Organizing & $22.58 \%$ & $19.10 \%$ \\
Leading & $31.68 \%$ & $21.50 \%$ \\
Coordinating & $46.81 \%$ & $19.30 \%$ \\
Controlling & $51.71 \%$ & $19.50 \%$ \\
Degree of Managerial Innovation & \multicolumn{2}{c}{$48.9 \%$} \\
\hline
\end{tabular}

$$
\delta M I=\frac{(W p \times P f)+(W o \times O f)+(W l \times L f)+(W c \times C F)+(W C o o r \times C o o r f)}{(W p+W o+W l+W c+W C o o r)} \times 100 \%=48.9 \%
$$

\section{Discussion}

PT. X business is in electronics for industry, covering train transportation, information technology and communication. PT Y business is in manufacture machineries and weapon system. Both are government owned companies, located in Bandung, West Java, Indonesia. In Planning function, PT X obtained 93.23\% and PT Y obtained 90.68\%. The differences is in element namely program, planned processes, and rolling plans. The score of PT Y is smaller than PT X because PT Y did not plan as they roll although there are some changes about technology and social outside the company. In Organizing function, PT X obtained 9.68\% and PT Y obtained 22.58\%. The score of PT Y is bigger than PT X because PT Y had 3 model of organization structure. In Leading function, PT X obtained $13.77 \%$ and PT Y obtained 31.68\%. PT Y has element namely participant. When there is production system, leader involved not complete but gave intention about what must to do for their manager. In controlling function, PT X obtained $47.75 \%$ and PT. Y obtained 51.71\%. PT. X focuses for controlling with element continuous \& self and PT Y focuses with using ERP. In Coordinating function, PT. X obtained $46.71 \%$ and PT. Y obtained $46.81 \%$. There is no differences between the element in Coordinating functions.

\section{Conclusion and Further Research}

The assessment method has been successfully implemented in Indonesian manufacturing companies. The score of managerial innovation of PT. X is $42.3 \%$ and PT. Y is $48.9 \%$. Hence, both companies 
should improve their management functions to improve capability in innovations. For further research, the model can also be applied in different sectors with some modifications, especially in the weight of the management functions.

\section{References}

1. Tidd J, Bessant JR. Managing innovation : integrating technological, market and organizational change. Chichester: John Wiley \& Sons; 2009. 622 p.

2. Ayhan MB, Oztemel E. A methodology to measure the degree of managerial innovation. J Ind Eng Manag. 2014;7(1):153-73.

3. Damanpour F, Aravind D. Managerial Innovation: Conceptions, Processes and Antecedents. Manag Organ Rev. 2012 Jul 2;8(2):423-54.

4. Blandine S, Nathan F. Impact of Managerial Innovation on Corporate Social Responsibility IKEA Case Study Analysis. Karlstad Business School; 2013.

5. $\quad$ Saaty TL. Decision making with the analytic hierarchy process. Int J Serv Sci. 2008;1(1):8398. 